\title{
Health services innovation: Evaluating process changes to improve patient flow
}

\begin{tabular}{|c|c|c|c|c|c|}
\hline & Author 1* & Author 2 & Author 3 & Author 4 & Author 5 \\
\hline Title & A/Prof. & $\mathrm{Dr}$ & $\mathrm{Dr}$ & A/Prof. & $\mathrm{Dr}$ \\
\hline Name & $\begin{array}{l}\text { J. Anneke } \\
\text { Fitzgerald }\end{array}$ & Kathy Eljiz & Ann Dadich & Terry Sloan & $\begin{array}{l}\text { Kathryn J. } \\
\text { Hayes }\end{array}$ \\
\hline Position & $\begin{array}{l}\text { Associate } \\
\text { Professor }\end{array}$ & Lecturer & $\begin{array}{l}\text { Research } \\
\text { Lecturer }\end{array}$ & $\begin{array}{l}\text { Associate } \\
\text { Professor }\end{array}$ & Research Fellow \\
\hline Affiliation & $\begin{array}{l}\text { University of } \\
\text { Western } \\
\text { Sydney }\end{array}$ & $\begin{array}{l}\text { Deakin } \\
\text { University }\end{array}$ & $\begin{array}{l}\text { University of } \\
\text { Western } \\
\text { Sydney }\end{array}$ & $\begin{array}{l}\text { University of } \\
\text { Western Sydney }\end{array}$ & $\begin{array}{l}\text { University of } \\
\text { Western Sydney }\end{array}$ \\
\hline Email & $\begin{array}{l}\text { A.Fitzgerald@u } \\
\text { ws.edu.au }\end{array}$ & $\begin{array}{l}\text { Kathy.eljiz@dea } \\
\text { kin.edu.au }\end{array}$ & $\begin{array}{l}\text { A.Dadich@uws. } \\
\text { edu.au }\end{array}$ & $\begin{array}{l}\text { T.Sloan@uws.e } \\
\text { du.au }\end{array}$ & $\begin{array}{l}\text { Kate.Hayes@u } \\
\text { ws.edu.au }\end{array}$ \\
\hline Telephone & $\begin{array}{lll}+61 & +2 & 4620 \\
3414 & & \end{array}$ & $\begin{array}{lll}61 & +3 & 9244 \\
6985 & & \\
\end{array}$ & $\begin{array}{lll}+61 & +2 & 9685 \\
9475 & & \end{array}$ & $\begin{array}{lll}+61 & +2 & 4620 \\
3239 & & \\
\end{array}$ & $\begin{array}{lll}+61 & +2 & 9685 \\
9477 & & \end{array}$ \\
\hline Address & $\begin{array}{lr}\text { Locked } & \text { Bag } \\
1797, & \text { Penrith } \\
\text { NSW, } & \text { Australia } \\
2751 & \\
\end{array}$ & $\begin{array}{l}70 \text { Elgar Rd, } \\
\text { Burwood VIC, } \\
\text { Australia } 3125\end{array}$ & $\begin{array}{lr}\text { Locked } & \text { Bag } \\
1797, & \text { Penrith } \\
\text { NSW, } & \text { Australia } \\
2751 & \\
\end{array}$ & $\begin{array}{lr}\text { Locked } & \text { Bag } \\
1797, & \text { Penrith } \\
\text { NSW, } & \text { Australia } \\
2751 & \\
\end{array}$ & $\begin{array}{lr}\text { Locked } & \text { Bag } \\
1797, & \text { Penrith } \\
\text { NSW, } & \text { Australia } \\
2751 & \end{array}$ \\
\hline
\end{tabular}

* Corresponding author

\section{Abstract}

In common with many countries, Emergency Departments (EDs) in Australia are under stress. To reduce "access block" (where service demands exceed the ED's capacity) work processes in the ED of a public hospital were analysed using animated simulation. This article describes organizational culture changes supported by the use of simulation as an impartial form of analysis and communication. Data collected included time stamps and booking schedules in the Imaging Department (ID), semi-structured interviews and patient flow observations from the ED to the ID. Implementation of ID staff-suggested improvements resulted in a $25 \%$ increase in the capacity of the Ultrasound department and a doubling of its ED cases. Improved communication between the ED and the ID as a direct result of this project has led to ongoing interdepartmental cooperation. One implication is that changes to health organisational culture can be assisted by computer simulations providing rapid and accurate predictions of change outcomes. 


\section{Introduction}

Within many Western health services, Emergency Departments (EDs) are under stress. The capacity of the EDs is one of the most pressing concerns for both policymakers and health department managers (NHHRCA, 2009; Fitzgerald, Sloan, Simoff, Samaranayake, \& Johnston, 2008). In Australia, the demand for emergency services is growing faster than the population. Since 2004-05, the demand for emergency services in the state of New South Wales (NSW) has increased by $6.9 \%$ annually, with more than $30 \%$ of residents visiting NSW EDs in 2006-07, of which $26 \%$ visited on more than one occasion (Booz Allen Hamilton, 2007).

The limited capacity of hospital EDs is evidenced by access block (ACEM2004; Cameron \& Campbell, 2003). Access block occurs when a patient remains in an ED for more than eight hours consequent to the limited availability of hospital beds (Paoloni \& Fowler, 2008). Recent statistics indicate that about thirty to forty percent of patients in NSW EDs exceed this eight-hour limit (Paoloni \& Fowler, 2008).

To help overcome access block in an ED, a study was undertaken to optimise patient flow by using interactive computing simulation to improve work processes (A. Fitzgerald, Dadich, \& Sloan, 2010). More specifically, visual analytics was used to map dynamic processes within an adjoining department deemed problematic by hospital personnel - namely, the Sonography Department. The map was informed by data, including the department layout; number of diagnostic rooms available; available equipment; staff rosters; procedure times; scheduling processes; and patient-wait periods. Using the software program, Tecnomatix Plant Simulation ${ }^{\circledR}$, data were integrated to provide a visual animation of the patient flow, superimposed on the layout of the department.

To assess opportunities for improvement, parameters influencing patient flow were manipulated using the software program. These included variables that influence room use including staffing, room availability and scheduling procedures. Simulating improvement strategies within a virtual environment had several benefits - strategies were tested instantaneously; they could be viewed as a visual animation; there was no disruption to existing hospital processes; and there was a reduced risk of resistance to change among clinicians.

The study demonstrated the potential value of process management tools in improving patient flow in hospital settings. It indicated that, using interactive animation, innovative ways to manage and deploy hospital resources can be tested virtually, devoid of the many challenges typically associated with trialling changes in the physical setting.

Despite the apparent value of this approach, the study also revealed the influence of stakeholder readiness on successful change management - a finding reflected elsewhere (Cunningham et al., 2002). This readiness can be constraint by organisational culture and the actors within it. Similar to previous research (Doolin, 2002), the study indicated that, within healthcare settings, occupational groupings and professional identities are an important consideration when implementing change.

The study culminated with the implementation of process changes to optimise patient flow. After identifying and testing different strategies, senior hospital personnel modified appointment times and staff availability (see Table 1). 
Table 1: Changes Implemented by the Hospital following the Patient Flow Study

Changes to Appointment Times

Appointment times were reduced from sixty to fifty-

minute timeslots per patient

Appointments were allocated to particular patient

groups - namely, eight emergency patient bookings,

eight inpatient bookings, six antenatal care patient

bookings, and two outpatient procedures for three

ultrasound rooms

One ultrasound room was dedicated to emergency

patients only, and appointments that were not

booked were allocated to inpatients

All ultrasound requests were to be ordered via an

electronic information system that gathers clinical

information to document patient care
Changes to Staff Availability

Three qualified sonographers were rostered to staff three ultrasound rooms each day

Each sonographer worked an average of eight days in ultrasound and other days in the general x-ray section of the imaging department - this served to minimise if not prevent repetitive occupational health related injuries

To allow for training of qualified sonographers and new trainees, plus coverage for annual and sick leave, an additional fulltime sonographer is required

This paper evaluates the effects of these changes. More specifically, it presents a process and an impact evaluation of the changes to optimise patient flow. The process evaluation helped to reveal 'the social processes involved in the delivery of the intervention, the reception of the intervention and the setting of the intervention' (Munro \& Bloor, 2010, p. 700), while the impact evaluation focused on 'determining the range and extent of outcomes' (Owen \& Rogers, 1999, p. 264).

Before presenting the evaluation results, this paper presents a brief review of literature from two relevant fields - animated computer simulation and organisational culture. The former is particularly germane to the impact evaluation of the implemented changes, while the latter is pertinent to the process evaluation of these changes. Following this review, the methods of evaluation and subsequent results are presented.

\subsection{Animated Computer Simulation}

Animated computer simulation involves elements of visual analytics, which is the science of methodical calculation facilitated by interactive visual presentation. Its strength is its pragmatism. Using graphical animated computer software, macro and micro processes can be depicted and modified, and subsequent effects can be surmised. As such, animated computer simulation provides predictive value, allowing users to experiment with innovative change without the need to pilot such change in vivo. As Thomas (2007) described:

People use visual analytics tools and techniques to synthesize information and derive insight from massive, dynamic, ambiguous, and often conflicting data; detect the expected and discover the unexpected; provide timely, defensible, and understandable assessments; and communicate assessment effectively for action ( $p$. 104).

Techniques that are simultaneously visual and interactive can be helpful for four key reasons (Cook, Earnshaw, \& Stasko, 2007). First, they can help users to understand complex data and situations where models alone are inadequate. Second, they readily detect 'trends and anomalies, evaluate hypotheses, and uncover unexpected connections' (p. 15). Third, through the use of contextual cues, 
they help the user to interpret the information presented. Finally, they encourage users to engage with and explore large datasets that might otherwise be daunting (Wong et al., 2006).

Although animated computer simulation can be used to guide organisational change, its technical functions have a limited capacity to implement and sustain such change. The success and sustainability of organisational change requires recognition of additional factors, including organisational culture, which includes healthcare settings (Alas \& Vadi, 2003; Faull, Kalliath, \& Smith, 2004; McAlearney, Fisher, Heiser, Robbins, \& Kelleher, 2004; Worthington, 2004).

\subsection{Organisational Culture}

Culture represents an important building block for organisations. According to Schein (2004), organisational culture might be understood as:

A pattern of shared basic assumptions that was learned by a group as it solved its problems of external adaptation and internal integration, that has worked well enough to be considered valid and, therefore, to be taught to new members as the correct way to perceive, think, and feel in relation to those problems (p. 17).

Organisational culture is influenced by actors within the organisation. These include opinion leaders, change agents and champions (Greenhalgh, Robert, Macfarlane, Bate, \& Kyriakidou, 2004). Although there is much overlap in their roles, discrete definitions are presented for ease of clarity.

Opinion leaders 'provide information and advice about innovations to many other individuals in the system' (Rogers, 2003, p. 26). Their ability to influence the views, attitudes and intentions of their colleagues is well recognised (Doumit, Gattellari, Grimshaw, \& O'Brien, 2007). Healthcare professionals are more likely to consider the opinion of someone they deem as professionally similar and credible (Lam \& Schaubroeck, 2000; Weimann, 1991). As such, innovation adoption may be aided by opinion leaders who support and advocate change within the organisation.

Influence is also exerted by change agents. Change agents are personnel who are able to effectively interact and negotiate with various stakeholder groups (Tatli \& Özbilgin, 2009). This may involve backstage activities (Buchanan \& Boddy, 1992) - that is, the 'covert manipulation of language, relationships, and organization structures' (Buchanan \& Badham, 1999, p. 616).

Also influential within an organisation are champions. A champion is the 'charismatic individual who throws his or her weight behind an innovation, thus overcoming indifference or resistance that the new idea may provoke in an organization' (Rogers, 2003, p. 414). They are typically authorised to instigate significant change; yet, it is their appeal that helps to allure others and orchestrate informal coalitions that embrace change. Their personality is such that they are able to interact with various individuals and groups with seeming ease. The influence of opinion leaders, change agents and champions can be swayed by employee resistance. Resisters may limit or even block the adoption of innovations - this can be achieved actively (Piderit, 2000) or passively, as demonstrated by 'agreeing verbally but not following through, feigning ignorance and withholding information' (Bolognese, 2002, p. 3).

Understanding an organisation's culture, and the ways in which its actors interact, is particularly important in the context of healthcare settings. This is because, although clinical factors help to 
determine patient scheduling, so too does the discretion of, and communication between clinicians, managers and practitioners (A. Fitzgerald, Dadich, \& Lum, 2007; J. Fitzgerald, Lum, \& Dadich, 2006; J. A. Fitzgerald, Lum, \& Dadich, 2008).

Although the study site - a sonography department, is part of a public hospital, it would be unwise to assume that its culture is identical to that of the hospital. This is because, unlike other departments that encompass both project- and process-driven stakeholders, the sonography department largely encompasses project-driven stakeholders. More specifically, other departments largely involve doctors whose primary focus is the patient-as-project (that is, patient treatment), as well as nurses whose primary focus is the patient-as-process (that is, patient care) (K. Eljiz, 2009). However, the sonography department involves a relatively smaller number of technical personnel who provide specialist services. As such, their primary focus is the patient-as-project, somewhat akin to doctors. This delineation between the sonography department and other departments, like ED, may hinder the ability to garner staff support when implementing change.

Informed by literature on organisational culture, this paper now evaluates the capacity of animated computer simulation to optimise patient flow in a sonography department. This is achieved through both process changes and an impact evaluation, as described in the following sections.

\section{Methods}

As part of a 2008 Sonography Project to optimise patient-flow between Emergency (ED) and Imaging Departments (ID), a visual animated computer simulation was applied to Sonography Department processes. The processes examined related to the scheduling of patients, the transportation of patients from the ward to the Imaging Department and back to the ward, and the preparation and ultrasound scanning of patients. As a result of the 2008 simulation project, several changes were made. These changes include changing 1 hour appointment times to 50 minutes, a dedicated room for ED patients, and the suggested re-allocation of one sonographer.

In the 2009 evaluation of results, both quantitative and qualitative data were collected and analysed. Two hundred and sixty eight cases were entered into Excel and analysed based upon the data from the 2009 ward orderly book. Qualitative data were also evaluated including semistructured interviews with key hospital informants and observation of departmental processes. The semi-structured interview themes centred on previous Imaging procedures with the Emergency department, process changes selected through the use of computer simulation and implemented, and the impact of the changes. Observation of the departmental processes in 2009 included the collection of time stamps of wait times for staff and patients to access the Imaging Department, transportation of patients from the wards to the Imaging department and back to the wards, and interactions between various functional and professional staff in the Emergency Department and the Imaging Department. These functional staff groups included managers and clinicians. Occupational groups included ward orderlies, bookings clerks, sonographers and radiologists, and doctors and nurses.

Initially, the interviews focused on the changes implemented to imaging department patient scheduling starting on February 9, 2009, and the subsequent use of animated computer simulation to communicate those changes to the various functional and professional groups. However, subsequent interviews revealed that some of the changes made were not well received by staff. 
Consequently, the interviews were expanded to include questions about future changes to processes related to scheduling, transporting, and scanning of hospital wide in-patients in the Imaging Department. Participants were also asked to suggest further improvements to the way that simulation tools are used in communicating potential future changes. The researchers interviewed staff members who were very familiar with the sonography department, its processes, and its relationship with other hospital departments in order to understand their perspectives about the changes. Interviews were conducted with three sonographers; two desk clerks; two medical directors; four managers and three ward orderlies.

Themes explored during the interviews included views about the changes to work processes, and perceived difficulties encountered in patient flow. To verify and validate the primary data collected, multiple staff were interviewed, and re-interviewed as additional issues arose. To prepare the data for analysis, the primary and secondary datasets were coded, cleaned, and integrated. More specifically, official records about sonography procedures and the wards that initiated the procedures were identified. Following this, the collected data were cleaned by excluding illegible, unclear or illogical records (for instance, improbable procedure times, as confirmed by the sonographers), and missing data were completed by referring to the ward orderly book and the booking records.

\section{Results}

In light of these identified benefits, this article now outlines the use of animated computer simulation to apply Lean Thinking to improve patient flow in a public hospital's ED (Fitzgerald et al., 2009, 1-3), and compares the results achieved with those predicted by animated computer simulation. The predictions from the 2008 simulation (column 1 in Table 2) are compared to the actual 2008 sonography performance (column 2 in Table 2 ) as shown below:

Table 2:

Hospital-Initiated Solutions Simulated

\begin{tabular}{|c|c|c|}
\hline Outcome Measure & $\begin{array}{l}\text { 50-Minute Timeslots } \\
3 \text { Rooms Open } \\
1 \text { Dedicated ED Room } \\
\text { Staff Increase of } 1.0 \text { FTE }\end{array}$ & $\begin{array}{l}2008 \text { Situation } \\
\text { (6 ED timeslots if } 3 \text { rooms are in } \\
\text { operation) }\end{array}$ \\
\hline Waiting Time & $8 \mathrm{~min} 10 \mathrm{sec}$ & $4 \min 39 \mathrm{sec}$ \\
\hline Total Patients & 5,554 & 3,927 \\
\hline Inpatients & 2,276 & 1,784 \\
\hline Outpatients & 1,284 & 994 \\
\hline ED Patients & 1,994 & 1,149 \\
\hline Overtime Staff & $9 \mathrm{~min} 20 \mathrm{sec}$ & $8 \mathrm{~min} 43 \mathrm{sec}$ \\
\hline Room Utilisation & $75 \%$ & $54 \%$ \\
\hline Room Utilisation incl. weekends & $13 \%$ & $13 \%$ \\
\hline Sonographer Utilisation & $85 \%$ & $85 \%$ \\
\hline
\end{tabular}

A comparison of the 2008 data revealed that whilst there were 2,580 annualised cases based upon the 430 cases analysed, the 2009 data revealed that there were 3,216 annualised cases based upon 268 cases analysed. This represents a $24.65 \%$ increase in the number of procedures performed. 
The overall actual achievement 2009 (annualised) was less favourable than predicted by the simulation of changes proposed. This may be explained by a variance in outpatient services, including a reduction of outpatients by $25 \%$ (from 201 to 160), rather than the predicted $600 \%$ increase, which would have been supported by the increase in available time slots. In addition, the ED is not using its available time slots optimally, as demonstrated by the inability to achieve predicted outcomes determined by available slots (516 rather than 1,994$)$.

As predicted, changes including increasing staff availability, altering the scheduling system and reducing timeslots from sixty to fifty minutes, have increased overall patient throughput by $25 \%$ (from 2,580 to 3,216 ). Nevertheless, the changes employed by the hospital have demonstrably assisted patient flow, increasing in-patient services by $19 \%$ (from 2,139 to 2,534) and Emergency Department patients by $114 \%$ (from 240 to 516). While this increase in throughput does not directly increase hospital bed capacity, the cause of access block, reduced imaging department delays speeds the diagnosis time for the ED leading to a more rapid discharge of ED patients. The increase in inpatient imaging also speeds the diagnosis time, enabling more rapid discharge directly freeing up bed capacity.

In addition, simulating potential process changes via computer animation in a virtual sonography department was well received by staff, and improved communication about objectives and potential changes between emergency and imaging departments. This is discussed in greater detail in the qualitative analysis section later in this article.

The following table (Table 2) compares results from the 2008 period (data collected before the simulation and proposed changes), the predictions of what would happen (with the implementation of the proposed changes), and results from the 2009 period (after the implementation of the changes). The actual results have been extrapolated to represent outcomes of a 12 month period, to match the timeframe utilised for the simulations.

Table 3: $\quad$ Outcomes of the Sonography Project

\begin{tabular}{|llllll|}
\hline Outcome Measure & \multicolumn{1}{c}{$\begin{array}{c}\text { Actual 2008 } \\
\text { (Annualised) }\end{array}$} & $\begin{array}{c}\text { Before change } \\
\text { simulation (2008) }\end{array}$ & $\begin{array}{c}\text { Predicted } \\
\text { Outcomes from } \\
\text { Simulation }\end{array}$ & $\begin{array}{c}\text { Achieved Outcome } \\
\text { 2009 (annualised) }\end{array}$ \\
\hline Waiting Time & $4 \mathrm{~min} 39 \mathrm{sec}$ & $4 \mathrm{~min} 39 \mathrm{sec}$ & $8 \mathrm{~min} 10 \mathrm{sec}$ & $6 \mathrm{~min} 9 \mathrm{sec}$ \\
\hline Total Patients & 2,580 & & 3,927 & 5,554 & 3,216 \\
\hline Inpatients & 2,139 & $(72.9 \%)$ & 1,784 & 2,276 & $2,534(78.8)$ \\
\hline Outpatients & 201 & $(7.8 \%)$ & 994 & 1,284 & $160(5.0)$ \\
\hline ED Patients & 240 & $(9.3 \%)$ & 1,149 & 1,994 & $516(16.2)$ \\
\hline
\end{tabular}

The simulated outcomes in each case (2008 and 2009) overestimated the achieved outcomes as the simulations assume all available capacity can be utilised. In any department maximum capacity will not be realised due to unforseen eventualities. For example, the increased staffing was not implemented immediately in 2009 due to difficulties experienced in recruiting qualified sonographers. In addition, the dedicated room for ED sonography patients assumes a constant stream of ED patient, which is not the case. However, the predicted near doubling of throughput from the ED was achieved. 


\subsection{Qualitative Findings}

Semi-structured interviews, conversations, and observations revealed positive as well as negative views regarding the changes made. The interview transcripts were compared to identify common themes and concepts. The team of researchers met frequently to discuss the themes and constantly question the data and construction of meaning. By comparing commonalities and differences amongst the various researchers, a more robust understanding of the data was achieved. An analysis of the interview data revealed five main areas of perceived issues. These areas include booking schedule, booking system, staffing profile, transportation, and issues with wards.

\subsubsection{Booking Schedule}

There were mixed feelings about the change from 1 hour time slots to 50 minute timeslots for bookings. Some of the responses received included:

- Perceptions of reduced flexibility to make changes to the bookings

- Sonographers were happy with the 50 minute time slots because they had adequate time to finish procedures

- The new system made it more difficult to take bookings because staff had to keep referring to the chart in the office with the new times

- Preference of half hour and 1 hour time slots

\subsubsection{Booking System}

Whilst changes made were to computerise the booking schedule, staff raised concerns about the new booking system. Some of the concerns included:

- Changes to the booking system needed to be captured to recognise when and why these changes had been made

- Reshuffling of patients was a huge problem

- Recommendation that the new booking system that was being introduced should be modified to capture and report on booking changes

\subsubsection{Staffing Profile}

The staffing profile of the imaging staff also attracted feedback. The majority of the feedback mentioned the inability of all staff to perform all procedures. Only one staff member was skilled enough to conduct all the procedures the department conducted. Additionally, the feedback given included:

- Skill mix remained a problem

- Available hours of each staff member is limited and varies

- Training internally takes time

- Not all staff can do all procedures

\subsubsection{Transportation}

During the first sonography project, there had been a perception by staff that a large part of the issue with patient flow in sonography was as a result of ward orderlies slowing down the process. 
However, this was not supported by the data. During the evaluation interviews with staff, the following comments were given:

- There is still the perception that ward orderlies are not as efficient as they could be

- Reshuffling of patient pick up at ward between orderlies is inefficient

- Staff (ward orderly) lack of availability due to sick days etc is an issue as it means there are less staff to transport patients

- Issues with wards

The general feeling from the Imaging staff and the Emergency Department staff interviewed was that another result of the sonography project was reduced tension between the two departments. However, there were perceptions that service to other wards could be improved. Specifically, the feedback received included:

- There is less pressure from the ED because of allocated timeslots for them. Now other wards want their own time slots (e.g. Stroke for carotid patients)

- Ward orderlies should verify that patient is ready for transportation before they visit the ward

- Ward orderlies should call ahead, but in some instances nurses on the ward will not answer the phone

- Time can be wasted at wards because the scheduled patient is in shower, eating, or has been discharged

Overall, there has been an improvement in the communication between the ED and the Imaging Department. One staff member stated:

There's better communication between the ED [emergency department] and Imaging I think because of more face-to-face communication. We're helping each other out, and we're getting a chance to see more of the pressures that each department has. We've always had that shifting of the blame, but now we meet so often that we get a chance to discuss the problems before they become too big.

In conclusion, analysis of the work processes and workload assisted to not only increase to the number of patients assisted but also to improve relations between different departments. Animated computer simulation provided different stakeholders with a formal reason to convene. It also provided a way to understand and improve a complex system.

\section{Conclusions and Implications for Managers}

The implemented process improvements resulted in a $25 \%$ increase in the capacity of the sonography department and a doubling of its capacity for cases from the ED. The staff-suggested process changes resulted in the capacity for ED patient ultrasounds more than doubling in the year following implementation.

During interviews with ID staff, the following suggestions for further improvement were made: 
To introduce six 50 minute slots and two 1 hour slots to allow for four short (30 minute) procedures.

Provide training so that all sonographers can conduct all procedures.

Ensure that ward orderlies call ahead to save time wasted on wards when patients are not ready or have gone home.

Use the new booking system should have a way of tracking the reshuffling.

Even though the implemented solution differed in some details from the solution recommended in 2008 , the increase in sonography throughput was still comparable to efficiency gain predicted from the 2008 analysis and simulation.)

Furthermore, interviews with ED staff confirm that sonography delays are no longer considered to be a major cause of ED access block.

In conclusion, the simulation project in 2008 predicted that allocating a separate sonography room dedicated to emergency patients would not improve timely provision of sonography services. In addition, grouping patients according to preparation versus non-preparation would not be helpful. However, simulation confirmed that re-allocating staff, altering the scheduling system and reducing timeslots from sixty to fifty minutes would increase patient flow. Hospital managers were also encouraged to consider the effects of providing outpatient services, including antenatal clinic services, within the acute hospital. This evaluation project has confirmed that patient flow has improved by employing strategies that were first tested in a virtual environment. In addition the evaluation shows that visual analysis of workflow problems improves communication between departments.

In addition to the improvements in patient throughput and communication, changes to the hospital's organisational culture were also assisted by using computer simulations to provide rapid and accurate predictions of change outcomes. In particular the simulations provided opportunities for clinicians and managers to trial potential solutions and identify changes that would achieve desired outcomes without inconveniencing staff or putting patients at risk. Full details of the impact of trialability, observability, low risk and other characteristics of the animated computer simulation in influencing individuals, groups and the organisation to adopt process innovations in the ID have been published previously (Eljiz, Dadich, et al., 2010; Eljiz, Hayes, et al., 2010; Hayes et al., 2010)

This research demonstrates that managers and clinicians who wish to change operational procedures in health care settings would be well advised to consider visual computer process animations as a communication tool to overcome preconceptions regarding operational procedures and interdepartmental relationships. In addition, the demonstrated benefits obtained in the Australian hospital may possibly be repeated in other service industries where conflict between strong occupational cultures hinders effective interdepartmental communication. 


\section{References}

ACEM (Australasian College for Emergency Medicine). (2004). Access block and overcrowding in emergency departments. West Melbourne, VIC: ACEM (Australasian College for Emergency Medicine).

Alas, R., \& Vadi, M. (2003, 22nd-24th May). The impact of organizational culture on organizational learning in six Estonian hospitals. Paper presented at the International Conference Enterprise in Transition, Tučepi, Croatia.

Bolognese, A. F. (2002, 12th May). Employee resistence to organizational change. Retrieved 11th Jan., 2009, from http://www.newfoundations.com/OrgTheory/Bolognese721.html

Booz Allen Hamilton. (2007). Key drivers of demand in the emergency department: A hypothesis driven approach to analyse demand and supply. Sydney, NSW: NSW Health.

Buchanan, D., \& Badham, R. (1999). Politics and organizational change: The lived experience. Human Relations, 52(5), 609-629.

Buchanan, D., \& Boddy, D. (1992). The expertise of the change agent. London: Prentice Hall.

Cameron, P. A., \& Campbell, D. A. (2003). Access block: Problems and progress. Medical Journal of Australia, $178(3), 99-100$.

Cook, K., Earnshaw, R., \& Stasko, J. (2007). Discovering the unexpected. IEEE (Institute of Electrical and Electronics Engineers) Computer Graphics and Applications, 15-19.

Cunningham, C. E., Woodward, C. A., Shannon, H. S., Maclntosh, J., Lendrum, B., Rosenbloom, D., et al. (2002). Readiness for organizational change: A longitudinal study of workplace, psychological and behavioural correlates. Journal of Occupational and Organizational Psychology, 75(4), 377-392.

Doolin, B. (2002). Enterprise discourse, professional identity and the organizational control of hospital clinicians. Organization Studies, 23(3), 369-390.

Doumit, G., Gattellari, M., Grimshaw, J., \& O’Brien, M. A. (2007). Local opinion leaders: Effects on professional practice and health care outcomes (Review) (No. CD000125): Cochrane Database of Systematic Reviews.

Eljiz, K. (2009). Who really matters: A mixed methods investigation into interoccupational and professional dynamics when managing patient flow. Unpublished Doctoral dissertation, University of Western Sydney, Sydney, NSW.

Eljiz, K., Dadich, A., Hayes, K. J., Fitzgerald, J. A., Sloan, T., \& Kobilski, S. (2010). Individual Factors Influencing the Diffusion of Process Innovations from Manufacturing to Health Services Settings. Paper presented at the 7th Biennial International Conference, Organisational Behaviour in Health Care (OBHC)

Eljiz, K., Hayes, K. J., Dadich, A., Fitzgerald, J. A., Sloan, T., \& Kobilski, S. (2010). Group Factors Influencing the Diffusion of Process Innovations from Manufacturing to Health Services Settings. Paper presented at the 7th Biennial International Conference, Organisational Behaviour in Health Care (OBHC).

Faull, K., Kalliath, T., \& Smith, D. (2004). Organisational culture: The dynamics of culture on organizational change within a rehabilitation center. Organization Development Journal, 22(1), 40-55.

Fitzgerald, A., Dadich, A., \& Lum, M. (2007). The operating theatre gridlock: How are decisions made on emergency surgical cases? Asia Pacific Journal of Health Management, 2(3), 21-29.

Fitzgerald, A., Dadich, A., \& Sloan, T. (2010). Doing more with less: Ways to improve patient flow in hospital settings. Asia Pacific Journal of Health Management, 5(2), 36-46.

Fitzgerald, A., Sloan, T., Simoff, S., Samaranayake, P., \& Johnston, M. (2008). Visual workflow and process optimisation: A method of analysis for patient flow in the hospital emergency department. Paper presented at the ANZAM (Australian and New Zealand Academy of Management) Conference.

Fitzgerald, J., Lum, M., \& Dadich, A. (2006). Scheduling unplanned surgery: A tool for improving dialogue about queue position on emergency theatre lists. Australian Health Review, 30(2), 219-231.

Fitzgerald, J. A., Lum, M., \& Dadich, A. (2008). How can human technology improve the scheduling of unplanned surgical cases? In N. Wickramasinghe \& E. Geisler (Eds.), Encyclopaedia of healthcare information systems (pp. 686-694). Hershey, PA: Medical Information Science Reference.

Greenhalgh, T., Robert, G., Macfarlane, F., Bate, P., \& Kyriakidou, O. (2004). Diffusion of innovations in service organizations: Systematic review and recommendations. Milbank Quarterly, 82(4), 581-629.

Hayes, K. J., Dadich, A., Fitzgerald, J. A., Sloan, T., Eljiz, K., \& Kobilski, S. (2010). Organisational Factors Influencing the Diffusion of Process Innovations from Manufacturing to Health Services Settings. Paper presented at the 7th Biennial International Conference, Organisational Behaviour in Health Care (OBHC)

Lam, S. S. K., \& Schaubroeck, J. (2000). A field experiment testing frontline opinion leaders as change agents. Journal of Applied Psychology, 85(6), 987-995. 
McAlearney, A. S., Fisher, D., Heiser, K., Robbins, D., \& Kelleher, K. (2004). Developing effective physician leaders: Changing cultures and transforming organizations. Hospital Topics, 83(2), 11-18.

Munro, A., \& Bloor, M. (2010). Process evaluation: The new miracle ingredient in public health research? Qualitative Research, 10(6), 699-713.

NHHRC (National Health and Hospitals Reform Commission). (2009). A healthier future for all Australians: Final report. Barton, ACT: Commonwealth of Australia.

Owen, J., \& Rogers, P. (1999). Program evaluation forms and approaches (Second ed.). Sydney, NSW: Allen \& Unwin.

Paoloni, R., \& Fowler, D. (2008). Total access block time: A comprehensive and intuitive way to measure the total effect of access block on the emergency department. Emergency Medicine Australasia, 20(1), 1622.

Piderit, S. K. (2000). Rethinking resistance and recognizing ambivalence: A multidimensional view of attitudes toward an organizational change. Academy of Management Review, 25(4), 783-794.

Rogers, E. M. (2003). Diffusion of innovations (Fifth ed.). New York, NY: Free Press.

Schein, E. H. (2004). Organizational culture and leadership (Third ed.). San Francisco: Jossey-Bass.

Tatli, A., \& Özbilgin, M. (2009). Understanding diversity managers' role in organizational change: Towards a conceptual framework. Canadian Journal of Administrative Sciences, 26(3), 244-258.

Thomas, J. J. (2007). Visual analytics: Why now? Information Visualization, 6(1), 104-106.

Weimann, G. (1991). The influentials: Back to the concept of opinion leaders? Public Opinion Quarterly, 55(2), 267-279.

Wong, P. C., Rose, S. J., Chin, G. J., Frincke, D. A., May, R., Posse, C., et al. (2006). Walking the path: A new journey to explore and discover through visual analytics. Information Visualization, 5(4), 237-249.

Worthington, F. (2004). Management, change and culture in the NHS: Rhetoric and reality. Clinician in Management, 12(2), 55-67. 